\title{
Exploration into the Development and Reformation of "Internet + Continuing Education": A Study Illustrated by Jiangyin Polytechnic College
}

\author{
Wei $\mathrm{CaO}^{1, \mathrm{a}}$ \\ ${ }^{1}$ Jiangyin Polytechnic College, Jiangyin, Jiangsu Province, China \\ a392906850@qq.com
}

\begin{abstract}
Keywords: "Internet+ "; higher vocational school; continuing education; innovative development.
\end{abstract}
\begin{abstract}
Influenced by series of new technologies, ideas and models, such as cloud computing, big data, MOOC and so on, education informationization has made great progress in China. The deeper integration of Internet and education, the iterative update of educational content, the virtual reconstruction of learning process experience, the innovative changes of educational forms, the diversity of educational evaluation have increasingly become our new normal in "Internet + education". In this paper, the development and reform of continuing education in Jiangyin Polytechnic College has been studied. With the top-level design and development plan of "Internet + continuing education", higher vocational schools work out the scientific plans and carry out the reforms. And therefore, they make good achievements. This paper had found that "Internet + continuing education" will revolutionary promote the development and reform of continuing education in higher vocational schools. And the research ideas and general requirements of "Internet + continuing education" have been formed, which will contribute to the development and reform of continuing education in higher vocational schools.
\end{abstract}

\section{Introduction}

In 2013, the CEO of Tencent, Pony Ma, has firstly proposed the concept of "Internet + ". He pointed out that Internet plus a traditional industry represents a kind of ability, or a kind of external resources and environment, which is an improvement of this on industry. In 2015, during the National People's Congress of the People's Republic of China and the Chinese People's Political Consultative Conference, Ma submitted a proposal named To Promote Domestic Economic and Social Innovative Development with "Internet + ", which appeals to adopt "Internet + " to encourage industrial innovation, promote cross-border integration, benefit people's livelihood and promote the innovative development of China's economy and society [1]. In the Twelfth National People's Congress (NPC) of the People's Republic of China in March, Premier LI Ke-qiang formally proposed that we should work out the plan of "Internet + ", promote integration between modern manufacturing and the mobile Internet, cloud computing, big data, Things of Internet, so that we could promote the healthy development of the Internet and Internet banking and guide the Internet enterprises to expand their international market.[2] In July, the State Council issued the document named Views on the Guidance of the Active Promotion of "Internet + ", which proposed that "Internet + " refers to the further integration of the Internet innovations and the fields of economy and society and so on. It promotes the technological progress, efficiency and organizational reform, enhances the real economy innovation and productivity and forms a more extensive phenomenon of economic and social development on the basis of Internet [3]. Therefore, "Internet + " has been changed from a concept to a basic national policy and has become an important strategy of China's economic construction and the development of structural transformation. It deeply integrates the Internet and other fields and it will create a new ecological and format. 


\section{Literature Review on "Internet + Continuing Education"}

On the basis of technical advantages include big data, cloud computing, mobile Internet, and the Internet thinking of "free use", Internet has affected all the fields of education and triggered the waves of reformation. The mode of "Internet + education" has become the inevitable choice for education industry's further development. The Internet and big data technology have brought infinite opportunities to the development of education industry, and how to make use of their advantages to achieve changes and innovation has become an important subject faced by education industry. XIE Ji-li points out that, Internet technology promotes the global informatization of education. The massive open online course "MOOC" and wisdom education, being as the products of "Internet + education", will decisively change future education [4]. LUO Xin-dong illustrates the development plight of continuing education in our country, and puts forward to a proposal which can improve the management system of continuing education in the era of the Internet [5]; YU Shi et al. explain that the Internet has changed the development methods of continuing education, while the close integration of lifelong learning and Internet will become the new development trend of continuing education. They also bring forward to an innovative concept of continuing education under the background of close integration between lifelong learning and the Internet [6]. ZHENG Li-ping et al. believe that under the background of Internet using, the design of continuing education system should be strengthened to meet the requirements of modern development; the service ability of continuing education should be improved to adapt the development of diversified learning methods; the innovation of continuing education teaching methods should be achieved to meet the demands of personalized learning; the standardization of continuing education courses should be carried out to meet the requirements of sustainable development [7]. Internet has broken the old development methods and rules of continuing education, while a series of institutional change, including the changes of teaching philosophy and teaching methods, the updating of teaching content, the innovation of service mode, and the reengineering of teaching system are just around the corner. Besides theoretical study, more explorations and researches on practice also need to be done.

\section{The Reforming Practice of "Internet + Continuing Education"}

Jiangyin Polytechnic College, which is also known as Jiangyin Open University, is the only higher vocational college run by Jiangyin government. It located in Jiangyin, which is a picturesque, watery city in the south of Yangze River. The city's economy ranks the first place in Jiangsu province for successive years; its economic competitiveness also takes the lead for consecutive thirteen years. There are more than 30,000 large and medium-sized enterprises in Jiangyin. These surrounding enterprise clusters provide powerful support for Jiangyin Polytechnic College. The school makes efforts in creating the "training center for front line talents", "training center for technical talents" and "service center for technology innovation". It focuses on the development and structural transformation of local industries and students' lifelong development. The college has put forward to a talent training target of "rooting in Jiangyin city and related enterprises, training production, operation and management talents with 'modern supervisors' potential for local economic and social development", and has formed the talent training mode of "two dimensions interaction, and two tracks parallel with each other" [8].

Continuing education School of Jiangyin Polytechnic College, hereinafter referred to as Continuing Education School, is the window of Jiangyin Polytechnic College's contribution to regional social and economic development. Its main functions are, to vigorously develop adult education-- both higher academic education and further non-curricula education-- of all types and at all levels; to actively explore the methods which can help the development of local economic structural transformation; to promote the construction of learning society, including learning villages and towns, learning-oriented enterprises and organizations; to improve the construction of Jiangyin lifelong education system on the basis of "Jiangyin lifelong learning website"; to try to build 
"learning centers" for Jiangyin citizens, "training centers" for enterprises and outsourcing talents, as well as "test centers" for Jiangyin citizens' informationization.

The top-level design for "Internet + continuing education" development. Continuing education School has established a scientific plan for the "thirteenth five-year" project of continuing education development under the formulation of Jiangyin Polytechnic College and the concept of "Internet + continuing education" strategy. Firstly, we should further integrate adult education resources in colleges and universities from various levels, developing curriculum products such as MOOC and micro-lectures. Secondly, we should explore the credit accumulation and transformation system. On the basis of the provincial pilot project of educational reformation and the implement rules of Jiangyin Polytechnic College's reformation project, exploring new methods to achieve exam reformation, credits accumulation and transformation for people who participate in university-enterprise cooperation program, which is also known as "academic performance + professional skills" selection system. And, through this program, we should try to achieve the overall recognition and cohesion on achievements of different kinds of continuing education, and to promote the communication between different aspects of continuing education. Third, we should improve management regulations and systems in continuing education programs, try to intensify participants' efforts to improve their working skills and service quality, achieve the transition from standard quality management system to comprehensive quality management system, and promote the appraisal system based on performances during the mid-term of "thirteenth five-year" period. Fourth, we should develop the mobile application and WeChat public platform of "Jiangyin lifelong learning website", form the matrix public platform for Continuing Education School and set up the bridge from lifelong learning to citizens, to meet the various learning and development requirements of local residents.

Scientific action plan for "Internet + continuing education" program. During the "Twelfth Five-year" period, the quantity, quality and structure of students who attend adult higher education course have changed. Continuing education School timely adjusted its education targets, taking the concept of "keeping stable growth to guarantee education quality, focusing on transformation and development, contributing to the society and creating innovation points" as working strategy, choosing the idea of "marketing is key to adult education industry, while service is key to marketing" as its service concept, and taking the idea of "Internet + continuing education" as the development direction for promoting innovation. The school has made scientific action plan for "Internet + continuing education". Firstly, we should enrich the patterns of school-running. Based on the original continuing education programs, further analyzing SWOT of the project. Combing the work of pilot reforming project of Provincial Examination Authority and implementing rules of reformation project of Jiangyin Polytechnic College, Continuing Education School carried out a reformed examination program which needs the university-enterprise cooperation to independently select students in 2015. This program has achieved good results and effectively made up the weakness of other projects. Second, providing diversified teaching methods. Based on the idea of "education is a kind of service", carrying out experiential learning, collaborative learning and blended learning. We should explore a management system for the relationship between continuing education's socialization and consumers. We should provide students with tailored learning services. Third, we should take learners as the center of education, change the traditional teacher-centered teaching mode to students-centered mode, providing students with all-round, personalized, continuous learning services. Teaching resources, process and learning evaluation should also be students-centered. The role of the teacher needs to transfer from dominator to auxiliary and server of students' learning. Fourth, advocating educational entertainment and promoting the learning through games. Helping students to learn knowledge on the platform of Internet like playing games. We should promote the development of education with task-based teaching method, and provoking students' interest through the analysis of specific cases. Fifth, we should offer value-added education services for free. By using MOOC, providing students with global educational resources, and effectively connected related disciplines and skill certifications. Sixth, we should explore the application of educational big data and social CRM. Recording large amounts of data like teaching and learning behaviors in class, 
teaching process and learning outcomes through the network platform. The comprehensive analysis of educational big data can help educators to provide accurate service and marketing strategies to students.

Development and changes of "Internet + continuing education" practice. In order to implement the "Internet + continuing education" action plan, the Continuing Education School introduced the following action programs. First, we should use the WeChat public platform "Continuing education School" as the pioneer of Internet service. The platform has multiple functions such as recruitment publication, news broadcast, teaching and administration information release, querying and service information push. It provides students with a new learning platform and circles of friends, and is gradually replacing the website publication, telephone communication, group messaging and QQ group contacting. Second, we should plan to construct the third phase of "Jiangyin lifelong learning website" mobile platform. Making sure the daily push of online learning information, weekly WeChat activities organization, monthly offline seminar, quarterly offline cultural activities in community, annual selection of online learning stars. We should create the atmosphere of "learning at anytime, in anywhere and for anyone". Third, we should improve the teaching and administration platform of Continuing Education School, construct its second phase which can be used in mobile ends or APP in mobile learning platform, and promote the construction of continuing education curriculum system. Fourth, we should set up WeChat matrix platform for continuing education further to realize the goal of all-round lifelong learning in a single website. We should help the functional departments in government to build the ecological city of "Wise Jiangyin". Fifth, establishing and perfecting the social consumer relationship management system. Through modern social media like WeChat, easy markets, twitter, weibo and QQ, closely links with the students can be formed. We should interact with students effectively in these social media, and attracting more students through these rapid, thoughtful and personalized services provided by social media.

\section{Results of "Internet + Continuing education" Practice}

Following the "Internet + continuing education" action plan, Continuing Education School steadily promotes the development and reformation of continuing education, and obtains certain achievements. One is the promoting of Internet thinking, information technology and a series of teaching innovation. Network platform and WeChat platform have become important ways for Continuing education School in recruitment, publication and educational information release. The number of share and forward about recruitment information increases; enrollment quantity proportion becomes higher and higher. These platforms have positive effects to student's life, study and work; they can also help to realize the materialization of Internet thinking.

Second, the concept of "teaching and researching practice should be students-centered" has been accepted. Two important projects have been successfully concluded. They are the research topics of "System Construction and Innovative Development of Studying Center" in 2013, which belongs to China Central Radio and Television University and is hosted by Continuing education School; the study of "Construction and Research of Overall Quality Control System in Modern Distance Education" which belongs to philosophy of social science research topic which is organized by the Department of Education of Jiangsu Province in 2013. A set of students-centered service quality standards and evaluation systems have formed to ensure the transformation of student-centered education from the perspectives of system and action.

Third, we should enrich the learning resources on "Jiangyin lifelong learning website", introduce curriculum resources with short length, and building outstanding local course and micro lectures based on the local features of Jiangyin community. These efforts stimulate the learning enthusiasm of Jiangyin citizens. Now there's an increasing number of enrollment and courseware click rate, which promote the rapid construction and development of lifelong education system in Jiangyin. Fourth, developing pilot projects on continuing education outcomes' certification, credits' accumulation and conversion system. In the program of examination reformation, the cooperation with Changjiang Electric Technology Company, Jiangsu Jonghua Technology Company, Jiangyin Hengrun Heavy Industries Company and Jiangsu Sanfanghang Group tried "academic performance + professional 
skills" selection system, which basically achieved the credits accumulation and transformation, and built the embryo of "credit bank" for continuing education.

\section{Exploration Thinking of "Internet + Continuing education"}

Above all, the Internet has changed the traditional continuing education method in which teachers, classrooms and teaching materials serve the main way of knowledge learning. Now the society enters a new information age; the Internet information education technology integrates closely with teaching and education. On the basis of theoretical analysis and reformation practice, the author initially formed the research methods and general requirements of "Internet + Continuing education".

First, "Internet + continuing education" changed the development mode of continuing education. A hybrid teaching mode of "learning online, tutoring offline" is achieved. Resources like MOOC and micro lectures make the education content more suitable for adult learners who can only use fragmentary time to study. In terms of management and service, "Internet + continuing education" helps to achieve the diversification, personalization, and large-scale learning demands of further learning.

Second, the close integration of "Internet + lifelong learning" will become the development trend of continuing education. It puts forward to innovative requirements for continuing education, and provides a broad prospect of continuing education's development.

Third, in the time of "Internet +", top design and system construction are very important. Continuing education innovation must start from its top design. Through the researching of continuing education development characteristics and learning from the successful experience of developed countries, the strategic positioning and system design for continuing education can be succeed. When designing the top-level strategy, higher vocational colleges should make continuing education development plan accordingly. Reformation needs to be done from education concepts, management systems and operation mechanisms, teaching modes, teaching content, teaching methods and other aspects.

Fourth, in this "Internet +" era, the integration and development ability of resource capabilities and the service capacity will determine the peak level of the continuing education development. Teaching resources and service quality are two magic weapons for continuing education. The innovation in service mechanism is the main body of continuing education reformation in the new period.

Fifth, is the age of "Internet + ", the diversified teaching modes will directly affect learner's requirements. New types of teaching, such as interactive method, research type, flat type, reverse and blended modes appear constantly. The further learning's social ecosystems, learning communities and wisdom city will greatly satisfy the needs of different learners.

Sixth, in the age of "Internet + ", the curriculum standards of continuing education, credit banks, credit certification and the conversion and life-long learning system has been united. They mutually promote and harmoniously develop. The individualized courses and curriculum standards of continuing education is an important part of reform. The learners' credit storage, credit certification and the conversion will help to promote the standardization of continuing education courses and the regionalization of the pilot of credit bank, which will contribute to the construction of lifelong learning education system which integrates the continue education curriculum standards and credit bank.

\section{References}

[1] [2] SHU Wen-qiong. "Internet + ": Only open mind can achieve 1+1>2 [J]. Communications World, 2015, (03): 14.

[3] The State Council issued the document named Views on the Guidance of the Active Promotion of "Internet + [EB/0L]. [2015-07-05]. http://cpc.people.com.cn/n/2015/0705/c64387-27255055.html. 
[4] XIE Ji-li. "Internet + " Leads the Trend of Education Reform [J]. Journal of Chuxiong Normal University, 2015, (02): 85-88, 108.

[5] LUO Xin-dong. the system innovation of continuing education in the strategic transformation in the age of Internet [J]. Education and Vocation , 2015, (11): 76-78.

[6] YU Shi \& ZHANG Hua. Innovative Development under the Background of the Deep Integration of the Network and Lifelong Learning [J]. Continuing Education , 2015, (05): 6-8.

[7] ZHENG Li-ping, et al. Continuing Education Reform under the Background of the Deep Integration of the Network and Lifelong Learning [J]. Journal of Continuing Higher Education , 2015, (03): 7-11.

[8] To root in the fertile soil and yield fragrant peaches and plums: A brief introduction of Jiangyin Polytechnic College [J]. Jiangsu Higher Education, 2014, (06): 158. 